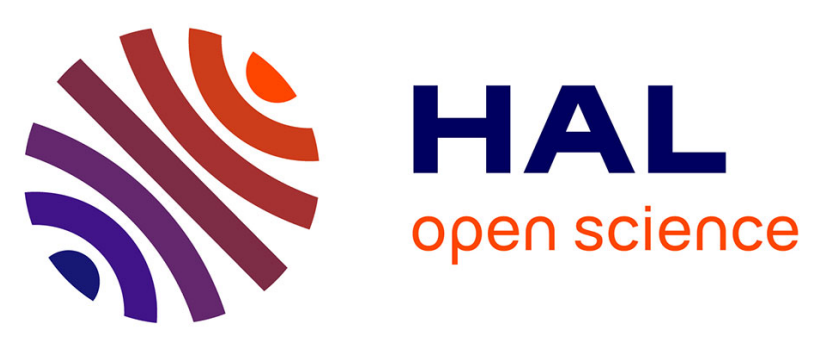

\title{
Linear and nonlinear MPC for track following in the design of HDD servo systems
}

Manel Taktak-Meziou, Ahmed Chemori, Jawhar Ghommam, Nabil Derbel

\section{To cite this version:}

Manel Taktak-Meziou, Ahmed Chemori, Jawhar Ghommam, Nabil Derbel. Linear and nonlinear MPC for track following in the design of HDD servo systems. International Journal of Systems, Control and Communications, 2014, 6 (1), pp.20-47. 10.1504/IJSCC.2014.06 lirmm-01718130

\section{HAL Id: lirmm-01718130 \\ https://hal-lirmm.ccsd.cnrs.fr/lirmm-01718130}

Submitted on 27 Feb 2018

HAL is a multi-disciplinary open access archive for the deposit and dissemination of scientific research documents, whether they are published or not. The documents may come from teaching and research institutions in France or abroad, or from public or private research centers.
L'archive ouverte pluridisciplinaire HAL, est destinée au dépôt et à la diffusion de documents scientifiques de niveau recherche, publiés ou non, émanant des établissements d'enseignement et de recherche français ou étrangers, des laboratoires publics ou privés. 


\title{
Linear and nonlinear MPC for track following in the design of HDD servo systems
}

\author{
Manel Taktak-Meziou* \\ Department of Electrical Engineering, \\ National School of Engineers of Sfax (ENIS), \\ BP, W 3038 Sfax, Tunisia \\ E-mail: manel.taktak@yahoo.com \\ *Corresponding author
}

\author{
Ahmed Chemori \\ LIRMM, \\ University Montpellier 2, \\ CNRS, UMR5506, CC477, 161 rue Ada, \\ 34095 Montpellier Cedex 5, France \\ E-mail: Ahmed.Chemori@lirmm.fr
}

\section{Jawhar Ghommam and Nabil Derbel}

Department of Electrical Engineering, National School of Engineers of Sfax (ENIS), BP, W 3038 Sfax, Tunisia

E-mail: jawhar.ghommam@gmail.com

E-mail: n.derbel@enis.rnu.tn

\begin{abstract}
This paper proposes to use the model predictive controllers (MPC) for servo control of hard-disk-drives (HDD). Nonlinear compensation of high-frequency dynamics is achieved using two control algorithms generated from model predictive control (MPC): classical linear MPC, and MPC technique with multiple coincidence points and a reference trajectory to ensure an exponential convergence towards the reference trajectory. At low-frequency, the resonance compensation is realised using nonlinear model predictive control (NMPC). This paper aims at applying the proposed predictive control solutions to resolve the track-following problem of the read/write $(\mathrm{R} / \mathrm{W})$ head of a HDD servo-system in different operating conditions. To the best authors' knowledge, these predictive methods and comparative study at low and high frequency regions have never been conducted before on HDDs. Different scenarios are analysed including nominal case, disturbance rejection, and robustness towards parameters change to show the effectiveness of the proposed control solutions in achieving a precise and fast $\mathrm{R} / \mathrm{W}$ head positioning. Numerical simulation results of the overall scenarios are presented and compared with those of a proportional integral derivative (PID) controller.
\end{abstract}

Keywords: hard-disc-drives servo-systems; linear predictive control; nonlinear predictive control; PID controller; disturbance rejection; track following; control design. 
Reference to this paper should be made as follows: Taktak-Meziou, M., Chemori, A., Ghommam, J. and Derbel, N. (2014) 'Linear and nonlinear MPC for track following in the design of HDD servo systems', Int. J. Systems, Control and Communications, Vol. 6, No. 1, pp.20-47.

Biographical notes: Manel Taktak-Meziou received her Engineer degree in Electrical Engineering from the National School of Engineering of Sfax (Tunisia) in June 2008. Then, she received her Master Science degree from the National School of Engineering of Sfax in June 2009. She is currently a PhD candidate, and her research activities concern the control of nonlinear systems using predictive approaches.

Ahmed Chemori received his BSc and MSc degrees in Electronics from the University of Constantine, Algeria in 1998 and 2000. He received his MSc in Automatic Control from Institut National Polytechnique de Grenoble (INPG), France. In 2005, he received his $\mathrm{PhD}$ in Automatic Control from Institut National Polytechnique de Grenoble (Department of Automatic Control), France. In 2004/2005, he has been a temporary teaching and research staff attached to the University Paris 11 and Laboratoire des Signaux et Systmes (LSS). In 2005/2006, he has been at Gipsa-Lab (Former LAG) as a postdoctoral researcher. Since 2006, he has been working at Laboratoire d'Informatique, de Robotique et de Microlectronique de Montpellier (LIRMM-UMR 5506) as 'Charg de recherche CNRS', where he conducts research in the area of nonlinear control of mechanical and robotic systems. His research topics includes: humanoid robot control, underactuated mechanical systems control and parallel robots control.

Jawhar Ghommam received his BSc in Computer and Control Engineering from the National Institute and Applied Sciences and Technology (INSAT) in 2003 in Tunis. He received his DEA (MSc) degree from the University of Montpelier at the Laboratoire d'Informatique, Robotique et Micro-lectronique (LIRMM, France) in 2004 under the supervision of Professor Franoit Pierot, and later on in $2008 \mathrm{a} \mathrm{PhD}$ in Control Engineering from the University of Orleans under the supervision of Professor Grard Poisson at the Laboratory of Vision and Robotics (LVR, France). From 2008 to present, he is with the National Institute of Applied Sciences and Technology, where he holds a tenured Assistant Professor at the Department of Electrical and Control Engineering Dr. J. Ghommam occupies a permanent research position at the Research Unit on Intelligent Control and Optimization of Complex System (ICOS) at Sfax-Tunisia.

Nabil Derbel received his Engineering Diploma from the National School of Engineering of Sfax in 1986, the DEA diploma in Automatics from INSA de Toulouse in 1986, PhD degree from the Laboratoire LAAS of Toulouse in 1989, and Doctorat dEtat degree from the National School of Engineering of Tunis in 1997. He joined the Tunisian University in 1989, where he held different positions involved in research and education. Currently, he is a Professor of Automatic Control at the National School of Engineering of Sfax. $\mathrm{He}$ is an IEEE senior member. His current interests include optimal control, fuzzy systems and neural networks.

This paper is a revised and expanded version of two conference papers: 'Model predictive tracking control for a head-positioning in a hard-disk-drive' presented at the 21st Mediterranean Conference on Control \& Automation (MED), Platanias-Chania, Crete, Greece, 25-28 June 2013; and 'Track following control using nonlinear model predictive control in hard disk drives' presented at the International Conference on Intelligent Robots and Systems (IROS'13), Tokyo, Japan, 3-7 November 2013. 


\section{Introduction}

Hard-disc-drives (HDDs) have been at the centre of the personal computer (PC) revolution during the last few decades. Indeed, in the past 20 years, HDD storage capacity grew from few Gigabits to several Terabits. Future evolution of these storage devices will require continuing innovation by research communities to improve their performance and capacities. A typical HDD is an assembly of several rotating disks called platters controlled by a spindle motor to ensure their high speed rotation. Data, which are arranged in concentric disks, are read or written by means of electromagnetic heads mounted at the end of several head arms. Such components are allowed to displace on the platters surfaces. Through a current control, a voice-coil-motor (VCM) actuator is dedicated to move the heads to reach the desired data track. The main components of a typical hard-disk-drive are illustrated in Figure 1. There are two main functions for a HDD servo-system. First, it ensures a prompt displacement of the $\mathrm{R} / \mathrm{W}$ head from its current track to another target position using a limited control effort (track seeking mode). Second, it accurately positions the head on the required track while information are being read or written (track-following mode). The control is often subject to various run-outs which have to be treated properly and compensated as much as possible. The low frequency modelling of the actuator is influenced by nonlinear effects of frictions and flexures generated from the movements of the reading or writing phases of the head. The high frequency VCM dynamics can be expressed as a linear transfer function including several resonance modes. Both nonlinearities and resonance modes present a great challenge since they are the major source of degradation of the servo-system performance. To deal with these challenges, many control solutions have been proposed in the literature for linear or nonlinear models of the drive. These solutions range from classical approaches such as PID controllers (Isayed and Hawwa, 2007), lead-lag compensators (Ishikawa and Tomizuka, 1998), and different filters (Atsumi et al., 2007), to more advanced control solutions including adaptive control (Horowitz and Li, 1995; Kobayashi, et al., 2004), sliding mode control (Yamaguchi et al., 1997; Yamaguchi and Hirai, 1998; Venkataramanan et al., 2002), robust control (Nie et al., 2011; Graham and De Callafon, 2006; Hirata et al., 2003), robust and perfect tracking (RPT) (Goh et al., 2001), composite nonlinear feedback (CNF) control (Chen et al., 2003), and more recently predictive control (Taktak et al., 2012, 2013) and prediction based state feedback control (Lee and Suh, 2011). Although much efforts have been managed, more control approaches need to be developed for such servo-system to better meet the required performance. As an effective control method, model predictive control (MPC) has been proposed in this paper to solve the path following problem of a R/W head servo-system. MPC was successfully applied to a wide range of linear and nonlinear systems. This success is attributed to its numerous advantages, including the ability to easily handle constraints on the system's variables, and to predict the future behaviour, enabling the design of an appropriate control law (Mayne et al., 2000; Mayne and Michalska, 1990). Moreover, many previous applications proved that MPC can guarantee closed-loop stability with minimal computational time (Nicolao et al., 1998). 
Figure 1 View of a typical hard-disk-drive (see online version for colours)

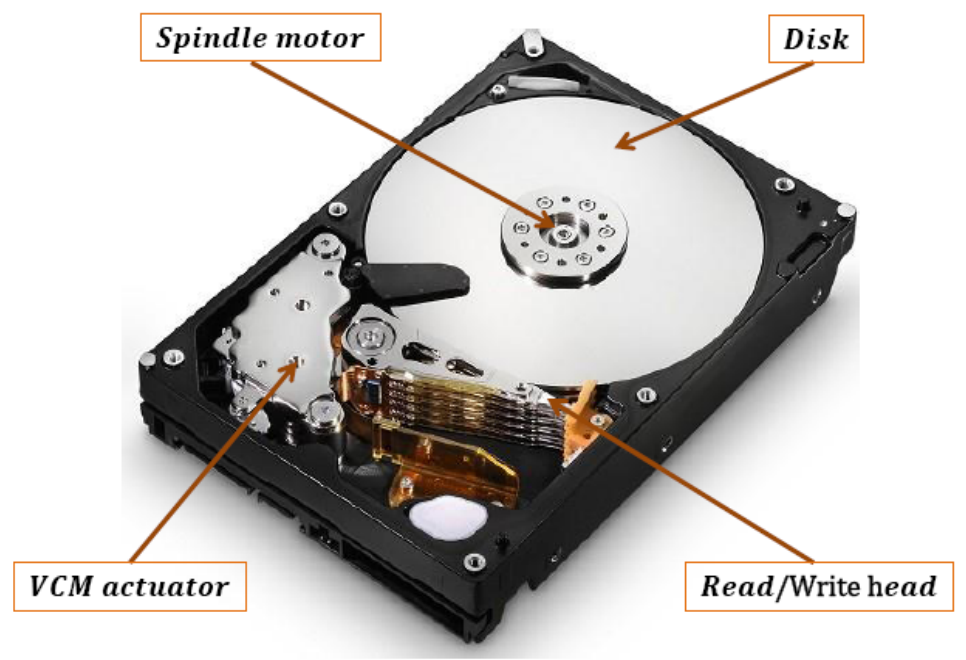

Motivated by the multiple benefits of MPC control, the paper aims at applying some of its techniques to resolve the track-following problem of the HDD servo-system. In spite of the different methods available for the HDD control servo-system, none applied a predictive controller to deal with its various practical challenges. The main purpose of this paper is to demonstrate that MPC techniques can achieve an accurate $\mathrm{R} / \mathrm{W}$ head positioning and to guarantee tighter tracking errors tolerance in both high and low frequencies working regions of a HDD. The proposed predictive control scheme will be studied for its effectiveness to reject disturbances generated by the head's motion, to mitigate resonances modes and nonlinearities, and to deal with different operating conditions.

The outline of this paper is as follows: in Section 2, a comprehensive modelling of the VCM actuator in low and high frequency regions is presented. In Section 3, the control problem statement is introduced. Section 4 presents the linear and nonlinear proposed MPC control solutions. In Section 5, simulation studies are presented and discussed. Finally, concluding remarks are drawn in Section 6.

\section{Dynamic modelling of the system}

In this section, a dynamic modelling of a VCM actuator is presented based on a detailed theoretical and experimental study of the frequency response identification of a HDD (Chen et al., 2006; Boettcher et al., 2010). Two different models are presented, one for high frequency and the second for low frequency. 


\subsection{High-frequency dynamics}

At high frequencies, and due to its imperfection, a VCM actuator is often modelled with a double integrator cast with some resonant modes. These resonant modes are mainly caused by the quasi-rigid body of the drive and its flexible modes which increase the system vibrations. All these factors have to be considered when designing an effective controller for the VCM. If neglected, they can degrade the performance of the controlled system and even cause instability. A realistic model of a commercial HDD (Model 51536U3), can be expressed by the following transfer function:

$$
G(s)=\frac{k_{v} k_{y}}{s^{2}} \prod_{i=1}^{N} G_{r, i}(s)
$$

where $k_{y}$ is the position measurement gain, $k_{v}=\frac{k_{t}}{m}$, where $k_{t}$ is the current-force conversion coefficient. $m$ is the mass of the VCM actuator, $N$ is the number of resonance modes and $G_{r, i}$ represent the transfer functions of the different resonant modes for $(i=1, \ldots, N)$. Using the detailed frequency response identification proposed in Chen et al. (2006), the following tenth-order model is obtained.

$$
G(s)=\frac{6.4013 \times 10^{7}}{s^{2}} \prod_{i=1}^{4} G_{r, i}(s)
$$

with

$$
\begin{aligned}
& G_{r, 1}(s)=\frac{0.912 s^{2}+457.4 s+1.433 \times 10^{8}}{s^{2}+359.2 s+1.433 \times 10^{8}} \\
& G_{r, 2}(s)=\frac{0.7586 s^{2}+962.2 s+4.249 \times 10^{8}}{s^{2}+789.1 s+2.491 \times 10^{8}} \\
& G_{r, 3}(s)=\frac{9.917 \times 10^{8}}{s^{2}+1,575 s+9.917 \times 10^{8}} \\
& G_{r, 4}(s)=\frac{2.731 \times 10^{9}}{s^{2}+2,613 s+2.731 \times 10^{9}}
\end{aligned}
$$

For high-frequency dynamics, the objective is to develop a linear model predictive controller that allows the R/W head of the HDD to follow a specified target track of data. A notch filter is introduced as a pre-compensator to mitigate the effect of the different resonance modes and maintain the overall performance of the close-loop system. The selected notch filter in this paper is the one proposed by Chen et al. (2006).

\subsection{Low-frequency dynamics}

At low-frequencies, the HDD servo system's dynamics is highly influenced by nonlinearities and frictional effects mainly inducted by the pivot bearing and the data flex cable. The R/W head is steered by the VCM actuator to move from its actual position to a desired track precisely and quickly. This displacement is carried out through a rotary pivot bearing. The data flex cable, which is connected to the $\mathrm{R} / \mathrm{W}$ head, is then subjected 
to contractions and expansions while the head tip browses data. Accordingly, several nonlinear effects are generated and must be compensated for to avoid misplacement of the $\mathrm{R} / \mathrm{W}$ head, which can lead to errors in reading or writing data as well as degradation in the performance of the HDD servo-system. Therefore, a great understanding of the physical characteristics of such nonlinearities and frictions is required for a precise modelling of the HDD servo system. The mathematical nonlinear model of the VCM actuator is given by

$$
M \ddot{y}+F(y, \dot{y})=u
$$

where $M$ is the system inertia. $y, \dot{y}$ and $\ddot{y}$ denote position, velocity and acceleration of the VCM-actuator head tip respectively. $u$ is the control input and $F(y, \dot{y})$ is a nonlinear function representing bias forces due to pivot friction or the flex-cable. Based on the detailed modelling and frequency response identification at low frequencies conducted by Boettcher et al. (2010), the nonlinear model of the VCM actuator, considered for our study, can be expressed by the following equations:

$$
\begin{aligned}
& \ddot{y}=2.35 \times 10^{8} u-6.7844 \times 10^{6} \arctan (0.5886 y)+T_{f} \\
& T_{f}=\left\{\begin{array}{cl}
-\left[\left|1.175 \times 10^{6} u y+0.01(\dot{y})^{2}\right|+15,000\right] \times \operatorname{sgn}(\dot{y})-282.6 \dot{y} & \dot{y} \neq 0 \\
-T_{e}, & \dot{y}=0,\left|T_{e}\right| \leq T_{s} \\
T_{s} \operatorname{sgn}\left(T_{e}\right), & \dot{y}=0,\left|T_{e}\right|>T_{s}
\end{array}\right. \\
& T_{e}=2.35 \times 10^{8}[-0.02887 \arctan (0.5886 y)+u] \\
& T_{s}=1.293 \times 10^{6}\left|u_{0} y_{0}\right|+1.65 \times 10^{4}
\end{aligned}
$$

where

$T_{f}$ nonlinear friction couple $(\mathrm{N} \mu \mathrm{m})$

$T_{e}$ external couple $(\mathrm{N} \mu \mathrm{m})$

$T_{s}$ breakaway torque $(\mathrm{N} \mu \mathrm{m})$

$u \quad$ input signal $(\mathrm{V})$

$u_{0} \quad$ input signal when $\dot{y}=0$

$y \quad$ output displacement (mm)

$y_{0} \quad$ output displacement when $\dot{y}=0$.

This servo system's nonlinear model is fully exploited to design an effective nonlinear model predictive controller (NMPC) capable of properly steering the $\mathrm{R} / \mathrm{W}$ head of a HDD.

\section{Problem statement}

In order to achieve a robust path following for the HDD servo-system, low and high frequency modelling must be used to develop control techniques capable of tuning the VCM actuator in various operating conditions. An effective controller must be able to 
maintain the $\mathrm{R} / \mathrm{W}$ head as close as possible to the target track centre such that the tracking errors are minimised. The proposed control solution must be enough robust to reject/compensate all these unwanted factors in the presence of external disturbances induced by the spindle rotation's effects (run-out media noise, windage, etc.) ( $\mathrm{Li}$ et al., 1997) and uncertainties on the HDD servo-system parameters. Therefore, our objective is to meet all the above criteria. The proposed control solution will focus on model predictive based control strategies. Such prediction feature of a controller makes this latter able to estimate the future behaviour of the system over a prediction horizon. Thereby, the cancellation of unwanted elements in the servo system can be achieved resulting in good performance of the closed-loop system. At high-frequencies, the HDD control structure is as shown in the block diagram of Figure 2. In this case, two model predictive based control solutions are proposed: classical linear MPC without constraints, and linear MPC with multiple coincidence points (MPC-CP). A detailed description of these two control techniques will be introduced in the following section. At low-frequencies, and in order to control the system described by (8) to (11), a nonlinear model predictive control (NMPC) is proposed. An illustrative schematic view of the proposed control structure is depicted in Figure 3.

Figure 2 Block diagram of the proposed control structure of the HDD at high-frequency (see online version for colours)

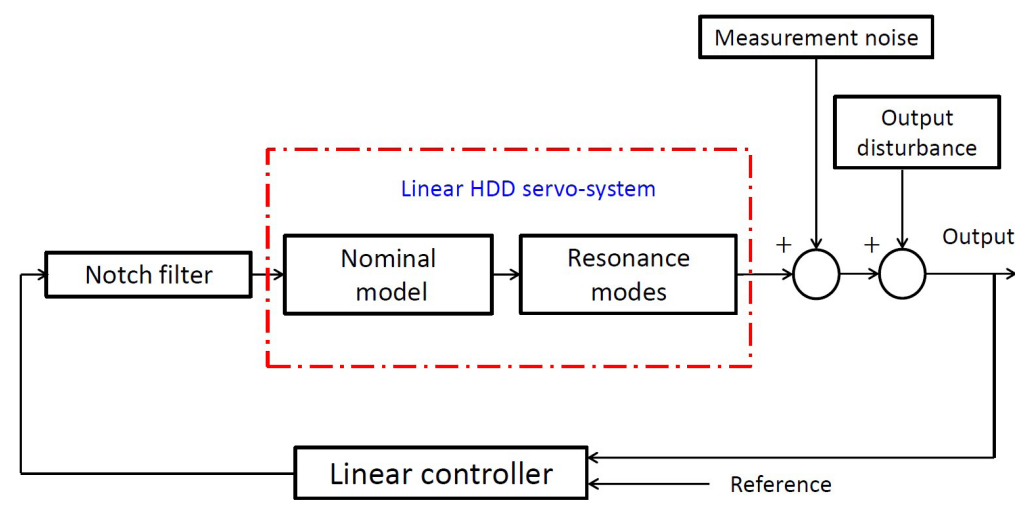

Figure 3 Block diagram of the proposed control structure of the HDD at low-frequency (see online version for colours)

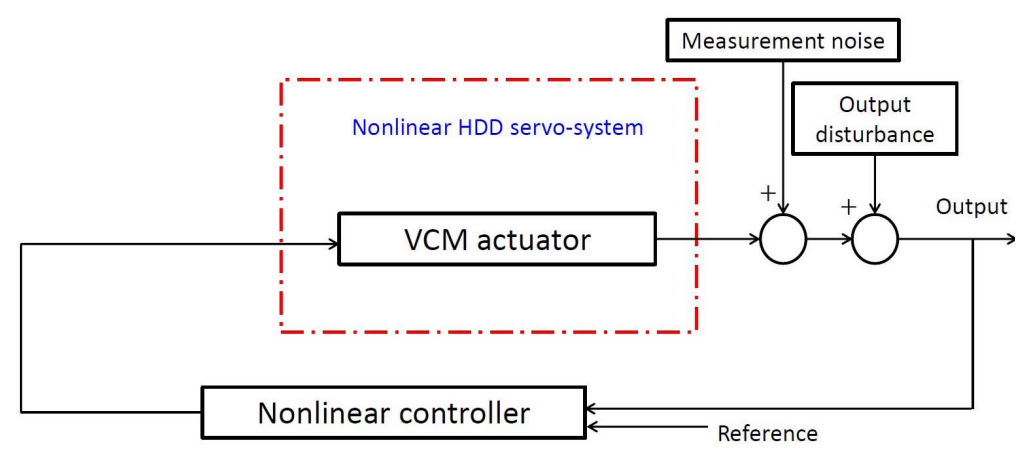




\section{Proposed solution: predictive control techniques}

In this section, we propose two solutions to control the $\mathrm{R} / \mathrm{W}$ head of a HDD servo-system. The main idea is to develop predictive control techniques and to take advantage of their capabilities to deal with the path following problem. As shown in Figure 2, linear predictive control solutions are designed to provide control at low-frequencies when the HDD has nonlinear dynamics. At high frequencies, the HDD is represented as a linear transfer function hitched with several resonances modes. As depicted in Figure 3, nonlinear MPC is designed to supply servo-control of the HDD.

\subsection{Background on model predictive control}

During the last decades, model predictive control (MPC) has gained an increasing interest from many researchers in various communities. The technique was mainly used to treat different optimisation problems (subject to constraints) to predict the future behaviour of the system and to design an appropriate optimal control signal. MPC is capable of ensuring good performance, even in the presence of constraints on the control inputs and on the state variables. These constraints are often not well addressed by other classical control schemes. An overview of this control approach is given in Clarke et al. (1987), and Qin and Badgwell (1996). Due to its properties and easy of implementation, MPC approach has become a popular control technique widely used in industry (Qin and Badgwell, 2003) and successfully applied to a wide range of different applications, especially those dealing with trajectory tracking problems. It includes applications in which the path to follow is well known a priori, such as robots (Camacho and Bordons, 2004) or robotic arms (Clarke, 1988), machine tools (Susanu et al., 2007), oil industry (Cutler and Ramaker, 1980; Garca et al., 1989), chemical or biochemical systems (Eaton and Rawlings, 1992; Cueli and Bordons, 2008), and aerospace (Bhattacharya et al., 2002). The basic principle of a predictive control is as illustrated in Figure 4.

Figure 4 Block diagram of a predictive control principle (see online version for colours)

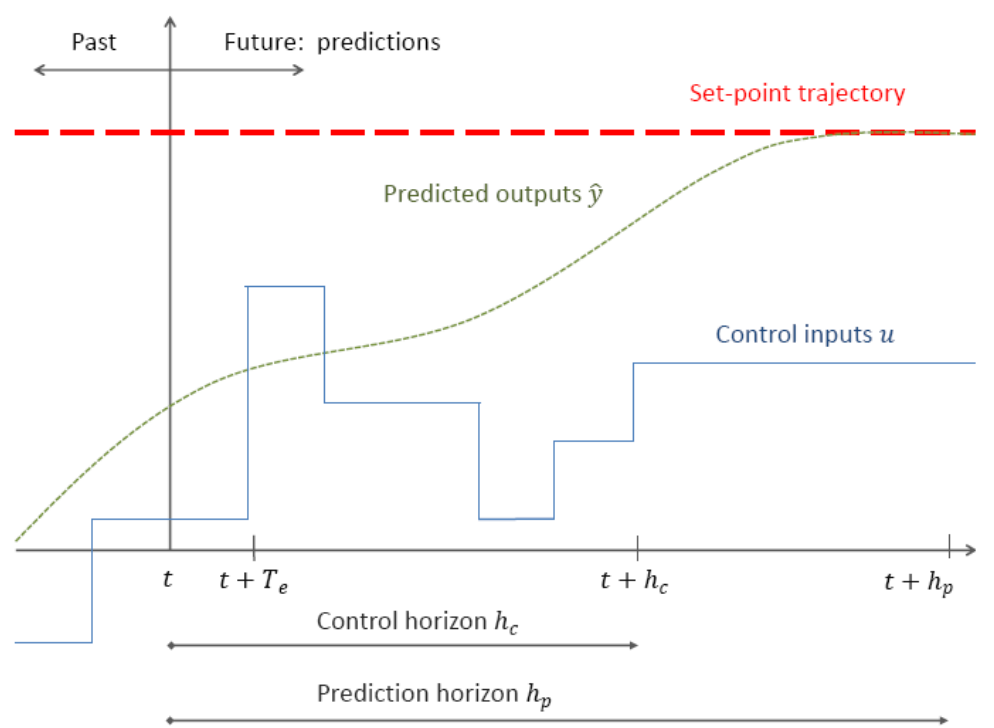


A general algorithm of the MPC technique, known as receding horizon strategy, can be formulated as follows:

1 At time instant $t$, the dynamic model is used to predict the future behaviour of the system, over a prediction horizon called $h_{p}$. Therefore, a sequence of estimated outputs is computed.

2 An optimal control sequence is calculated over a control horizon $h_{c}\left(h_{c} \leq h_{p}\right)$. The obtained control sequence derives, from the minimisation of a cost function (often quadratic) that allows the tracking of the desired set-point trajectory with respect to the imposed constraints.

3 Only the first sample of the optimal control sequence in applied to the system until the next sampling time $t+T_{e}$.

4 The prediction horizon is shifted and the procedure is repeated from (1) at the next sampling time.

The early applications of predictive controllers have been performed on linear systems to demonstrate their key benefits. Indeed, many algorithms were proposed in the literature including dynamic matrix control (Cutler and Ramaker, 1980), generalised predictive control (Clarke et al., 1987) and linear MPC-CP (Maciejowski, 2002). Linear MPC involves a finite horizon optimisation problem where the solution is analytically determined satisfying possible linear constraints on the control inputs and the state variables. However, the increasing demand for tighter specifications and higher quality of productivity has made linear models inadequate to describe complex dynamics. Therefore, the use of NMPC became necessary (Clark, 1994; Rawlings et al., 1994; Piché et al., 2000; Mayne and Michalska, 1990). In NMPC, a nonlinear programming tool is usually used to find an optimal solution. Many robust solvers have been proposed in the literature to find the optimal solution that guarantees the stability of the closed-loop system. Next, the mathematical formulations of linear MPC-CP and NMPC approaches will be presented.

\subsection{Linear MPC with coincidence points}

Consider that the system to be controlled is modelled by a discrete-time linear state space model as follows:

$$
\begin{aligned}
& x(k+1)=A x(k)+B u(k) \\
& y(k)=C x(k)
\end{aligned}
$$

where $x(k), u(k)$ and $y(k)$ are respectively the state vector, the control input and the output of the system at instant $k . A, B$ and $C$ are the matrices of the system, assumed to be known. This model is derived from the linear model of the HDD at high frequencies as given by (2) to (6). The generation of this latter and the definition of the different parameters were performed within the routine tf2ss and c2d of MATLAB environment. As stated before, a linear MPC-CP is a predictive control algorithm. The basic principle of this algorithm is to predict the process behaviour and optimise an objective function to generate an optimal control sequence over a control horizon. The resulting solution has to 
guarantee the stability, robustness and output tracking of a desired trajectory assumed to be well known a priori. The speed of response and simplicity of the MPC-CP approach makes it more attractive and widely used in different industrial applications (Maciejowski, 2002). One key idea of such a control scheme is that the prediction horizon is restricted to a small subset of points, called coincidence points. This feature makes calculations much simpler and the implementation of the proposed solution easier because the desired and predicted future outputs are required to coincide at only the considered points instead of the entire prediction horizon as in the classical MPC approach. Figure 5 illustrates the basic principle of the MPC-CP technique. The analysis of this basic principle will be discussed on a single input, single output system as described by (1). At instant $k$, the predicted output of the plant is denoted by $\hat{y}(k)$. Also shown in Figure 5 are two distinct trajectories: a set-point trajectory $s(k)$ which defines the path that the process output have to follow and a reference trajectory, denoted by $r(k)$, which defines an exponential form to steer the system's output from its actual position to the desired set-point. The current error at time $k$ is defined as:

$$
\varepsilon(k)=s(k)-y(k)
$$

Figure 5 The basic idea of MPC-CP approach (see online version for colours)

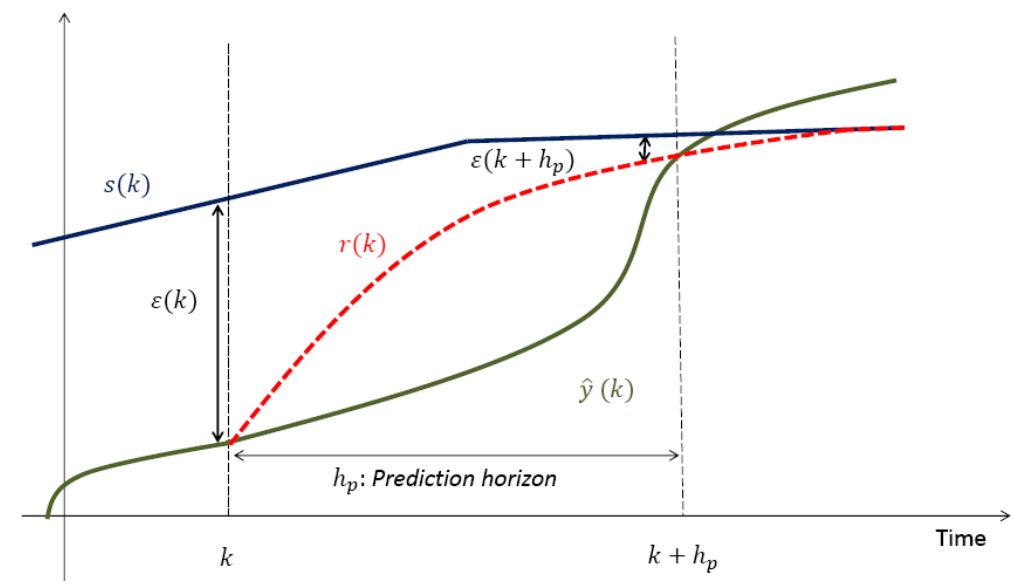

If the tracking is achieved perfectly, the reference is chosen such that the error, $i$ steps ahead, would be

$$
\begin{aligned}
\varepsilon(k+i) & =\exp ^{-i T_{s} / T_{\text {ref }}} \varepsilon(k) \\
& =\lambda^{i} \varepsilon(k)
\end{aligned}
$$

where $T_{\text {ref }}$ represents the time constant of the exponential reference trajectory and consequently defines the response speed, $T_{s}$ is the sampling interval and $\lambda=\exp ^{-T_{s} / T_{r e f}}$ verifying $0<\lambda<1$. Therefore, the reference trajectory at instant $k+i$ can be expressed as follows:

$$
\begin{aligned}
r(k+i \mid k) & =s(k+i)-\varepsilon(k+i) \\
& =s(k+i)-\exp ^{-i T_{s} / T_{r e f}} \varepsilon(k)
\end{aligned}
$$


$r(k+i \mid k)$ denotes the reference at time $k+i$ depending on the conditions at time $k$. The main purpose is to guide the system output to join accurately the reference trajectory. Therefore, coincidence points are mainly introduced to achieve this aim by ensuring $r\left(k+P_{i} \mid k\right)=\hat{y}\left(k\left|P_{i}\right| k\right), i=1 \ldots c$ which implies that the predicted outputs have to coincide with the reference trajectory at all the considered coincidence points. $c$ is the number of coincidence points. In general, the solution derives from a least square problem yielding the minimisation of the following objective function:

$$
\sum_{i \in P}[r(k+i \mid k)-\hat{y}(k+i \mid k)]^{2}
$$

where $P$ is the set of subscribes $i$ which corresponds to coincidence points.

As a general case, the input is assumed to change over $h_{c}$ steps ahead, so that the optimal control input sequence to find is $\hat{u}(k \mid k), \hat{u}(k+1 \mid k), \ldots, \hat{u}\left(h+h_{c}-1 \mid k\right)$. Since $\hat{u}(k \mid k)=u(k-1)+\Delta \hat{u}(k \mid k)$, the predicted future outputs can be written as:

$$
\begin{aligned}
\hat{y}\left(k+P_{i} \mid k\right)= & \hat{y}_{f}\left(k+P_{i} \mid k\right)+S\left(P_{i}\right) \Delta \hat{u}(k \mid k)+\ldots \\
& +S\left(P_{i}-h_{c}+1\right) \Delta \hat{u}\left(k+h_{c}-1 \mid k\right)
\end{aligned}
$$

$S\left(P_{i}-j\right)$ for $\left.j=0 \ldots h_{c}-1\right)$ is the step response of the model $P_{i}-j$ steps ahead. By rewriting equation (17) in a matrix form, the resulting predicted output vector at all the considered coincidence points is expressed as follows:

$$
Y=Y_{f}+\Theta \Delta U
$$

where $\Theta$ is the matrix of the step response given as

$$
\begin{aligned}
\Theta & =\left[\begin{array}{ccccccccc}
S\left(P_{1}\right) & S\left(P_{1}-1\right) & \ldots & 0 & \ldots & 0 & 0 & \ldots & 0 \\
S\left(P_{2}\right) & S\left(P_{2}-1\right) & \ldots & \ldots & \ldots & \ldots & 0 & \ldots & 0 \\
\vdots & \vdots & \vdots & \vdots & \vdots & \vdots & \vdots & \vdots & \vdots \\
S\left(P_{c}\right) & S\left(P_{c}-1\right) & \ldots & \ldots & \ldots & \ldots & \ldots & \ldots & S\left(P_{c}-h_{c}+1\right)
\end{array}\right] \\
\Delta U & =\left[\begin{array}{lllll}
\Delta \hat{u}(k \mid k) & \Delta \hat{u}(k+1 \mid k) & \ldots & \Delta \hat{u}\left(k+h_{c}-1 \mid k\right)
\end{array}\right]^{T}
\end{aligned}
$$

and $Y_{f}$ is the free response of the plant.

$$
Y_{f}=\left[\begin{array}{llll}
\hat{y}_{f}\left(k+P_{1} \mid k\right) & \hat{y}_{f}\left(k+P_{2} \mid k\right) & \ldots & \hat{y}_{f}\left(k+P_{c} \mid k\right)
\end{array}\right]^{T}
$$

The least-squares optimisation problem admits an optimal solution expressed as

$$
\Delta U=\Theta^{+}\left(\Gamma-Y_{f}\right)
$$

where $\Gamma$ is the matrix of the corresponding values of the reference trajectory at the different coincidence points expressed as

$$
\Gamma=\left[\begin{array}{llll}
r\left(k+P_{1} \mid k\right) & r\left(k+P_{2} \mid k\right) & \ldots & r\left(k+P_{c} \mid k\right)
\end{array}\right]^{T}
$$

$\Theta^{+}$is the pseudo-inverse of $\Theta$. As mentioned above, only the first sample of the computed optimal sequence $\Delta U$ is applied and the control input of the plant is then: 


$$
u(k)=u(k-1)+\Delta \hat{u}(k \mid k)
$$

For a complete review of this control technique, the reader is referred to Maciejowski (2002).

\subsection{Nonlinear MPC}

In this section, a brief review of NMPC is presented. This technique was frequently used for systems that are naturally nonlinear. The online optimisation based principle is mainly dedicated to predict the output of the plant and to find the best control sequence in terms of a minimised cost function in presence of different constraints. A general nonlinear discrete time state space system can be expressed as:

$$
\begin{aligned}
& x(k+1)=f(x(k), u(k)) \\
& y(k)=g(x(k))
\end{aligned}
$$

where $x(k) \in \square^{n_{x} \times 1}, u(k) \in \square{ }^{n_{u} \times 1}$ and $y(k) \in \square^{n_{y} \times 1}$ are respectively vectors of the states, control inputs and outputs at time instant $k$. This model derived from the nonlinear model of the HDD at low frequencies as expressed by (8) to (11). This second order differential equation was generated using the solver function ode45 of MATLAB environment. The common feature of MPC techniques is the minimisation of a cost function to compute the optimal control sequence. This function is generally a quadratic function including the future tracking errors predicted along a prediction horizon $h_{p}$ and $h_{c}$ control inputs.

$$
J=\sum_{j=1}^{h_{p}}\|e(k+j \mid k)\|_{Q}^{2}+\sum_{i=1}^{h_{c}}\|u(k+i \mid k)\|_{R}^{2}
$$

where $\|\mathbf{x}\|_{M}^{2}=\mathbf{x}^{\boldsymbol{T}} \boldsymbol{M \mathbf { x }} . \boldsymbol{Q}$ and $\boldsymbol{R}$ are the weighting matrices, with $\boldsymbol{Q} \geq 0$ and $\boldsymbol{R}>0$.

$$
e(k+j \mid k)=y_{d}(k+j \mid k)-\hat{y}(k+j \mid k)
$$

$y_{d}(k+j \mid k)$ is the reference trajectory to be followed, assumed to be known a priori and $\hat{y}(k+j \mid k)$ are the future predicted outputs over $h_{p}$ samples ahead. Constraints on the state and control variables are often expressed as follows:

$$
\begin{aligned}
& \mathbb{U}:=\left\{u \in \square^{n_{u} \times 1} \mid u_{\min } \leq u \leq u_{\max }\right\} \\
& \mathbb{X}:=\left\{x \in \square^{n_{x} \times 1} \mid x_{\min } \leq x \leq x_{\max }\right\}
\end{aligned}
$$

where $u_{\min }, u_{\max }, x_{\min }$ and $x_{\max }$ are the known bound vectors, $\mathbb{U}$ and $\mathbb{X}$ are the compact subsets of constraints. Since the optimisation problem in NMPC is a nonlinear programming which has to be solved online at each sampling period, an analytical solution remains difficult or even impossible to find. The fundamental idea consists of introducing predefined optimisation function to overcome the nonlinear computational complexity yielding the generation of the optimal control signal to be applied to the nonlinear system. 


\section{Application to the HDD: simulation results}

Different scenarios have been simulated for both high and low frequency models of the HDD servo-system. In this section, numerical simulations of each scenario are presented. A comparative study between the proposed control solutions and classical PID controller is made in order to show the efficiency and robustness of each controller to deal with the track following problem of a R/W head of a HDD. A physical constraint on the actuator is considered on the control input and introduced as a saturation $\pm 3 \mathrm{~V}$. In the first scenario, a step trajectory varying from 0 to $1 \mu \mathrm{m}$ is considered. A measurement noise, assumed to be a zero-mean Gaussian white noise, is introduced affecting the measurement. In the second scenario, simulations have been performed using a constant reference signal of $1 \mu \mathrm{m}$ while introducing an external disturbance. The main objective of this scenario is to test the ability of the proposed controllers to reject external disturbances. Such disturbance arises from the spindle motor rotation and its effects such as runout media noise, and windage. Finally, in the last scenario, uncertainties on the system's parameters are considered. A poor knowledge of these parameters can originate from the movement of the $\mathrm{R} / \mathrm{W}$ head while browsing the information on the disk. A good controller has to ensure that the output is as closer as possible to the desired trajectory despite any uncertainty on the model's parameters.

\subsection{Control of the HDD in high frequencies}

In this section, simulation results of a classical MPC, MPC-CP, and a PID controllers for the high frequency model of a HDD, are presented and compared. The considered model is the one described by equations (2) to (6). The measurement white noise variance is $\sigma^{2}=\times 10^{-4}(\mu \mathrm{m})^{2}$. The model's parameters are $m=0.01595 \mathrm{Kg}, k_{t}=1.0210 \times 10^{6}$ and $k_{y}=1$. Initial condition of the overall vectors is chosen at the origin. The sampling frequency is fixed at $20 \mathrm{KHz}$. Table 1 summarises the different synthesis parameters of the proposed controllers. An energy function $E$ is introduced to be used in the comparative study. It is expressed as follows:

$$
E=\sum_{i}\left|u_{i}\right|, i=\ldots N_{\text {sim }}
$$

where $N_{\text {sim }}$ is the number of samples for duration of simulation.

Table 1 Controllers synthesis parameters (linear case)

\begin{tabular}{|c|c|c|c|c|c|c|c|c|}
\hline \multicolumn{3}{|c|}{$P I D$} & \multicolumn{3}{|c|}{$M P C$} & \multicolumn{3}{|c|}{$M P C-C P$} \\
\hline$K p$ & $K i$ & $K d$ & $h p$ & $h c$ & $\bar{R}$ & $h_{p}$ & $h_{c}$ & $T_{r e f}$ \\
\hline $4.5 \times 10^{-3}$ & $2 \times 10^{-4}$ & 0.85 & 30 & 3 & $100 I$ & 5 & 2 & $5 \times 10^{-4}$ \\
\hline
\end{tabular}

\subsubsection{Scenario 1: nominal case with a measurement noise consideration}

The response of the closed-loop system with the different controllers is depicted in Figures 6 and 7. As it is shown in all cases the R/W head is able to follow the desired reference trajectory meeting the control specification. The predictive behaviour of the classical MPC and MPC-CP techniques is perceptible through Figures 6(b) and 6(c). Indeed, these controllers anticipate the change of the set-point trajectory $h_{p}$ samples 
before. This cannot be achieved with a classical PID where the response is slower and its overshoot is larger compared to the two predictive controllers. The overshoot with the MPC-CP controller is very small and the 5\% settling time is also short yielding the best performance.

Figure 6 Track following problem in nominal conditions: evolution of the output displacement, (a) with PID (b) with LMPC (c) with LMPC-CP (see online version for colours)

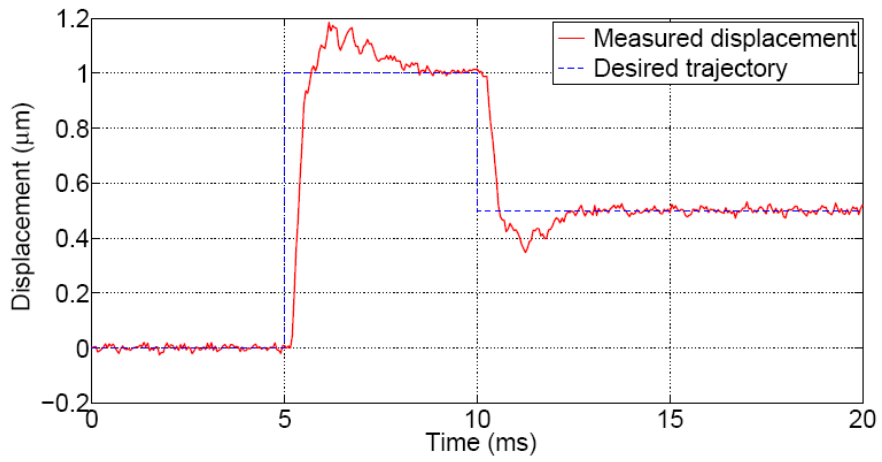

(a)

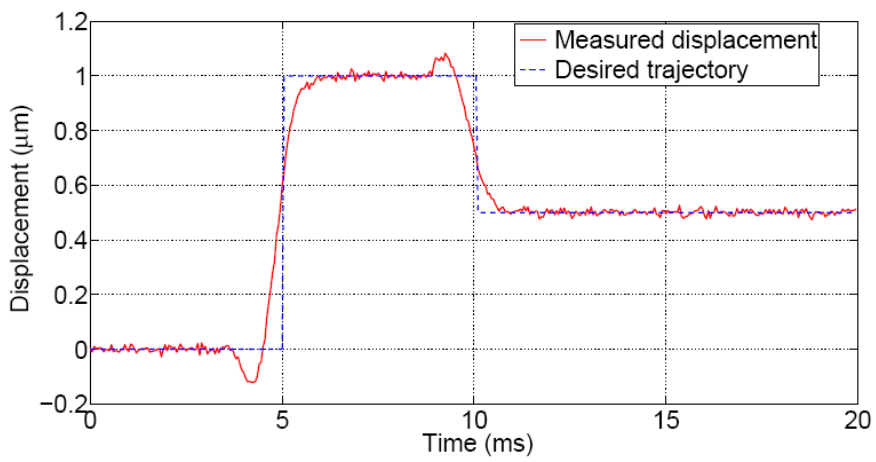

(b)

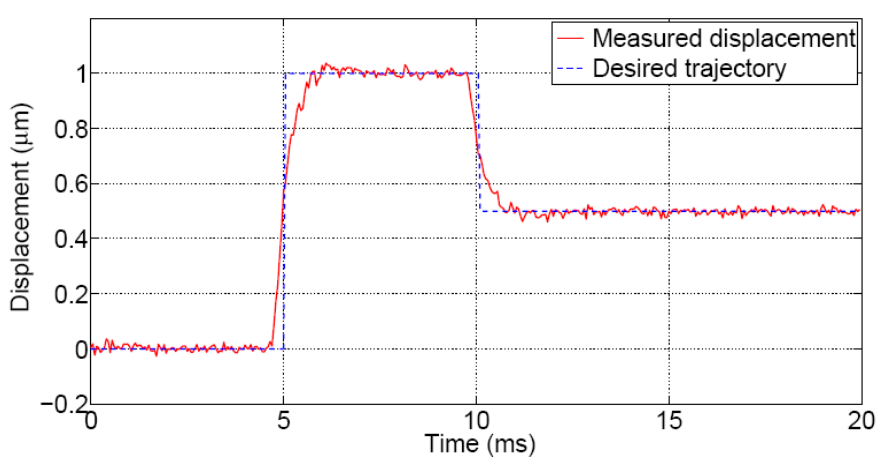

(c) 
Figure 7 Track following problem in nominal conditions: evolution of the control input, (a) with PID (b) with LMPC (c) with LMPC-CP (see online version for colours)

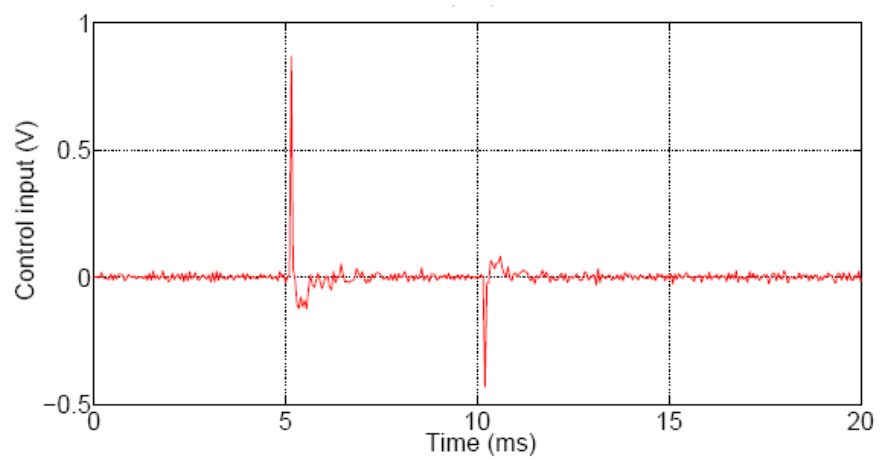

(a)

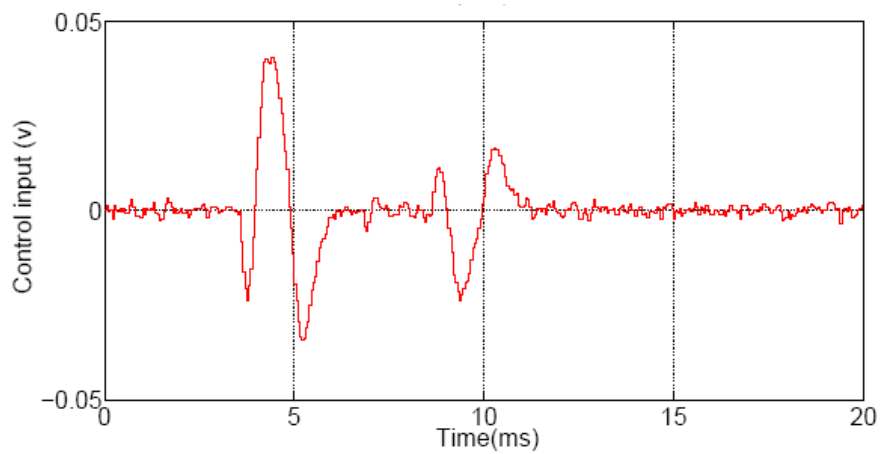

(b)

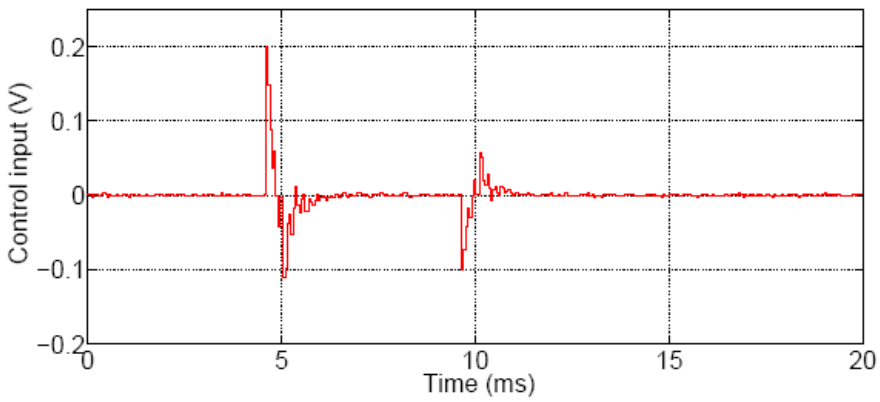

(c)

\subsubsection{Scenario 2: punctual disturbance rejection}

An unexpected disturbance can affect the HDD servo-system actuator. Figure 8 and Figure 9 show the closed-loop responses of the disk drive against an unexpected external impulse disturbance. With the classical PID, the rejection is achieved with large overshoots and a long recovering time. With the predictive controllers, the effectiveness in terms of disturbance rejection is much better. The actuator returns quickly to the desired trajectory and maintains it close to its target position. In terms of energy 
consumption, MPC-CP controller uses the least amount of energy. Numerical values for the high frequency study are reported in Table 2.

Figure 8 Track following problem with punctual disturbance: evolution of the output displacement, (a) with PID (b) with LMPC (c) with LMPC-CP (see online version for colours)

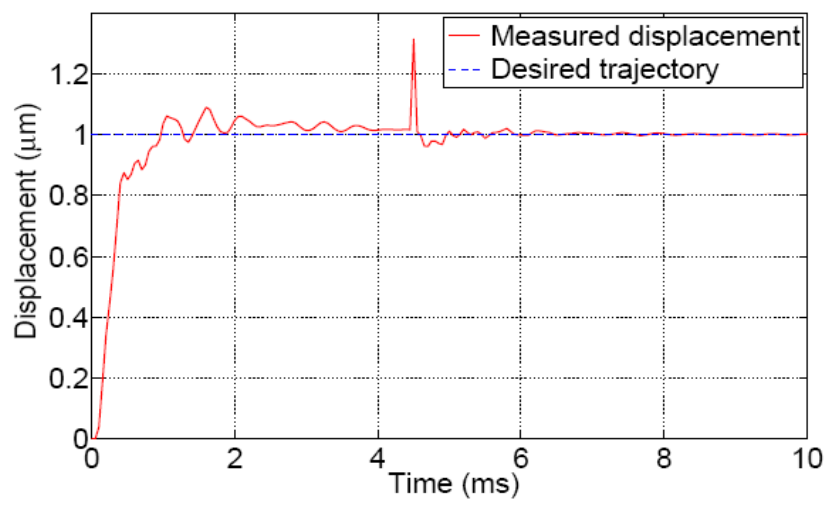

(a)

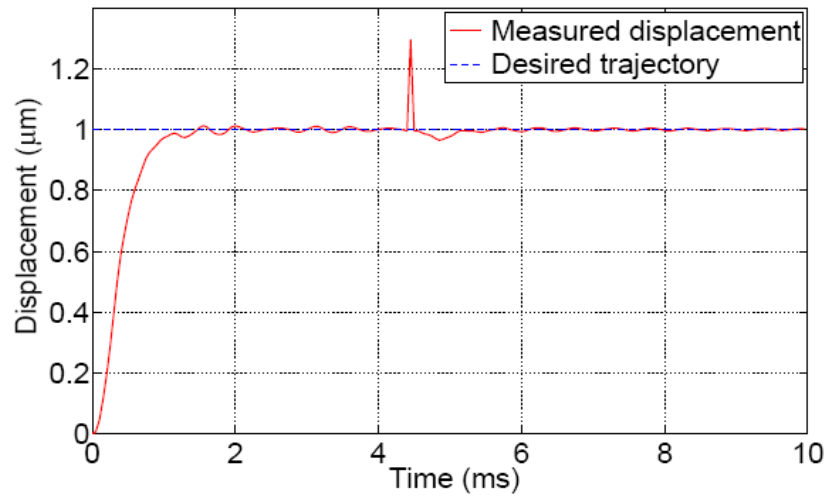

(b)

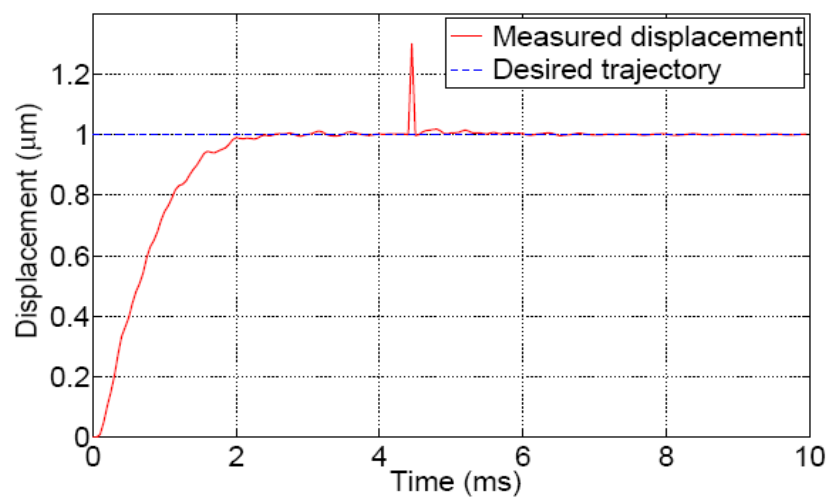

(c) 
Figure 9 Track following problem with punctual disturbance: evolution of the control input, (a) with PID (b) with LMPC (c) with LMPC-CP (see online version for colours)

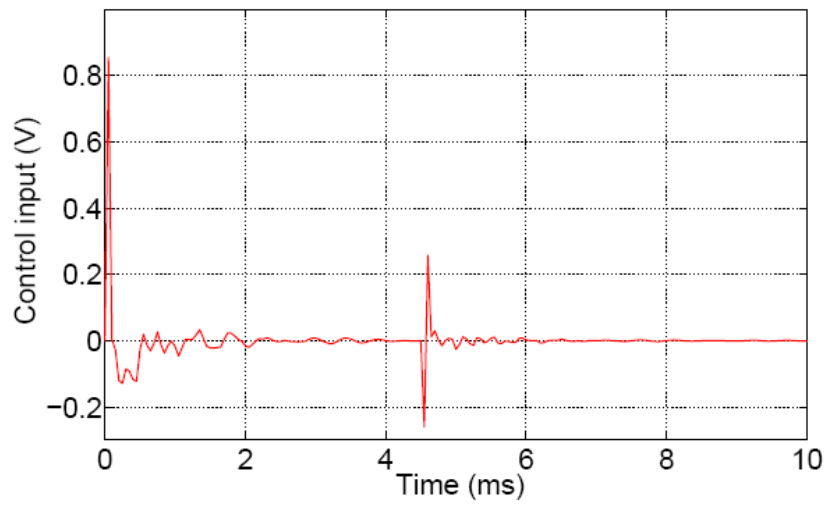

(a)

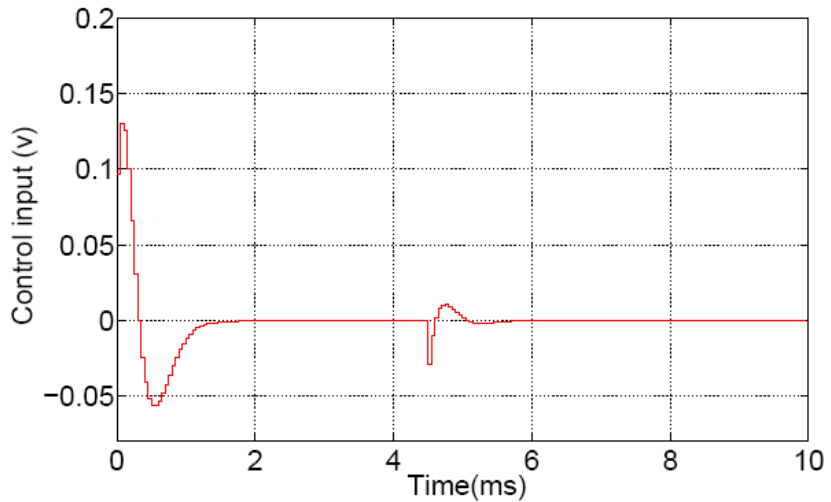

(b)

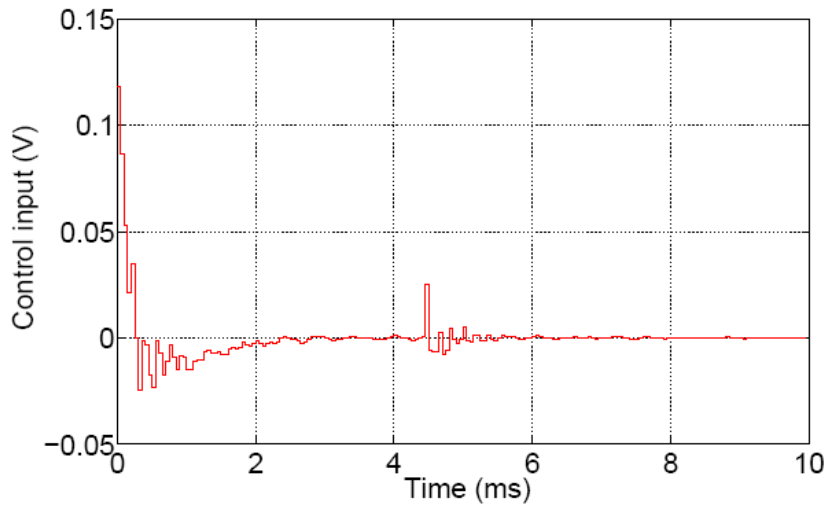

(c) 
Table 2 Controllers performance comparison in high frequencies

\begin{tabular}{lccc}
\hline Nominal case & PID controller & MPC controller & MPC-CP controller \\
\hline Settling time & $2.73 \mathrm{~ms}$ & $1.7 \mathrm{~ms}$ & $1.07 \mathrm{~ms}$ \\
Maximum overshoot & $19 \%$ & $13 \%$ & $4 \%$ \\
Energy function (E) & $6.5 \mathrm{v}$ & $1.79 \mathrm{v}$ & $1.94 \mathrm{v}$ \\
\hline Punctual disturbance & & & \\
\hline Recovery time & $2.05 \mathrm{~ms}$ & $1.05 \mathrm{~ms}$ & $1.2 \mathrm{~ms}$ \\
Maximum overshoot & $31.3 \%$ & $30 \%$ & $30 \%$ \\
Energy function (E) & $3.12 \mathrm{v}$ & $2.21 \mathrm{v}$ & $0.75 \mathrm{v}$ \\
\hline Parameters uncertainties & & & \\
(80\% of error) & & & $2.3 \mathrm{~ms}$ \\
\hline Settling time & $3.36 \mathrm{~ms}$ & $1.35 \mathrm{~ms}$ & $0.52 \%$ \\
Maximum overshoot & $28.13 \%$ & $16.2 \%$ & $1.05 \mathrm{v}$ \\
Energy function (E) & $5.07 \mathrm{v}$ & $1.37 \mathrm{v}$ & \\
\hline
\end{tabular}

\subsubsection{Scenario 3: Robustness against parameters uncertainty}

The simulation results for controller robustness against parameters uncertainty are presented in Figure 10 and Figure 11. The considered uncertainties are on the mass, the position measurement gain, and the current-force conversion coefficient of the VCM actuator. The best R/W head tracking is obtained with the MPC-CP controller as shown in Figure 10(c) and Figure 11(c). Even with up to 80\% parameter variation, the effect on the HDD servo-system behaviour is minimal. However, with a PID controller, the path following response is hardly affected by the uncertainties which are perceptible through the large time convergence and the observed high overshoots and oscillations. With a classical MPC, the closed-loop is much better than the classical PID especially in terms of convergence speed. Unfortunately, oscillations remain significant as depicted in Figure 10(b). Therefore, the MPC-CP approach is the best approach for dealing with parameter' changes and for achieving reduced overshoots and minimal settling time in steering the head of the HDD servo system to its desired position.

\subsection{Control of the HDD in low frequencies}

A comparison of low frequency, simulation results of a classical PID and a NMPC applied to control of the nonlinear VCM actuator are presented and discussed. The same previous three scenarios are evaluated for the effectiveness of each proposed control solution to meet performance and achieve a precise positioning of the HDD head tip. At low frequencies, the predictive algorithm is based on a nonlinear optimisation problem since the HDD is modelled with nonlinear dynamics. This makes it extremely difficult to find an analytical solution. Thus, the optimisation problem for the NMPC has been solved using the MATLAB routine fmincon including the considered control constraint. Table 3 shows a summary of the controller's parameters while Table 4 summarises the different controllers' performance. 
Figure 10 Robustness towards parameters' uncertainties: evolution of the output displacement, (a) with PID (b) with LMPC (c) with LMPC-CP (see online version for colours)

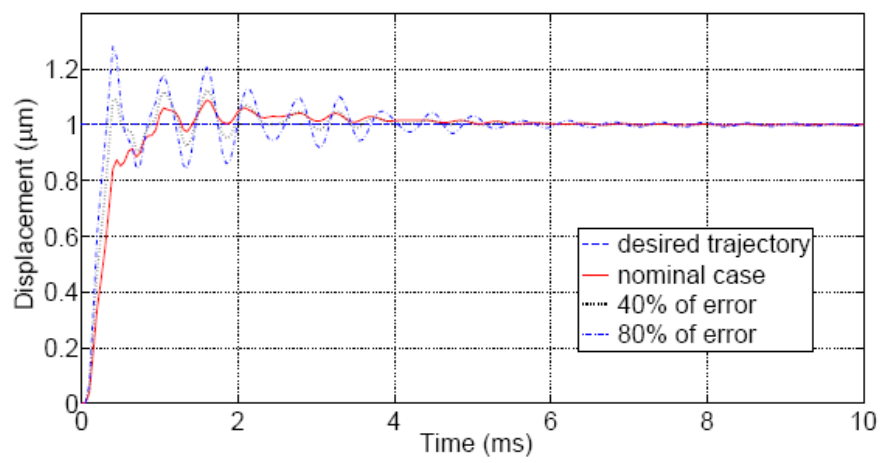

(a)

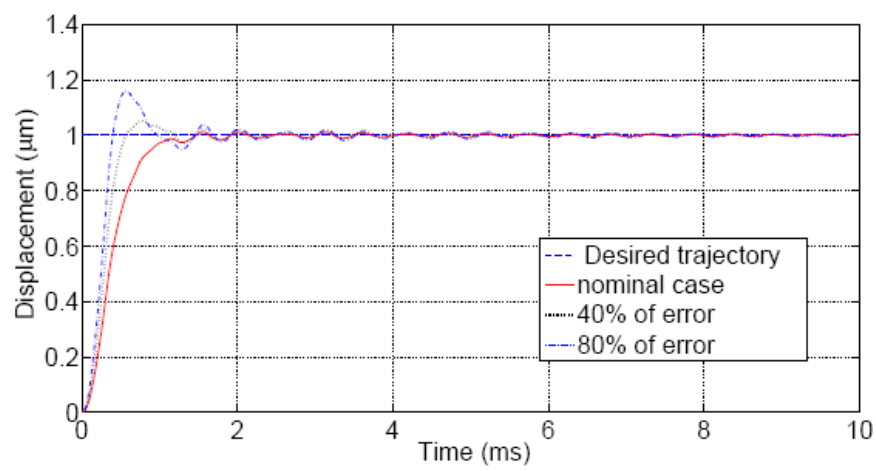

(b)

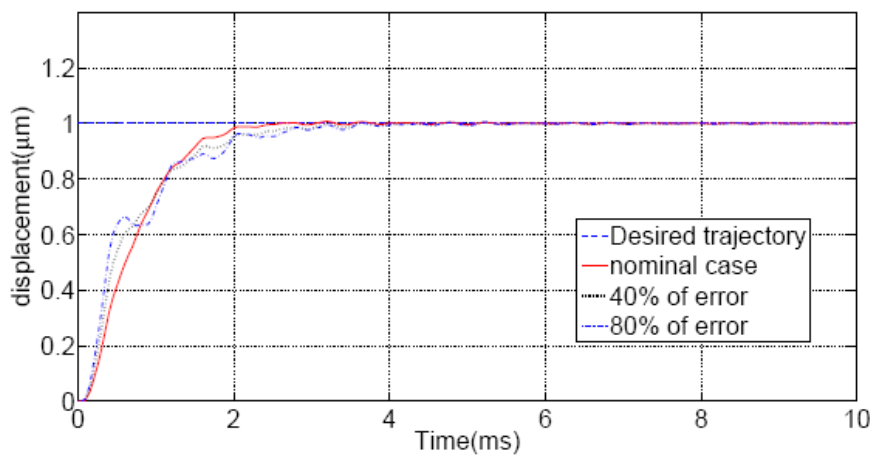

(c) 
Figure 11 Robustness towards parameters' uncertainties: evolution of the control input, (a) with PID (b) with LMPC (c) with LMPC-CP (see online version for colours)

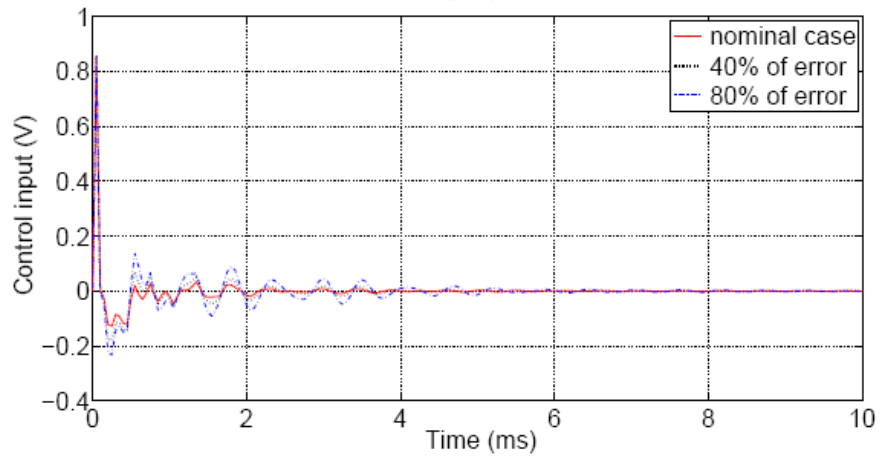

(a)

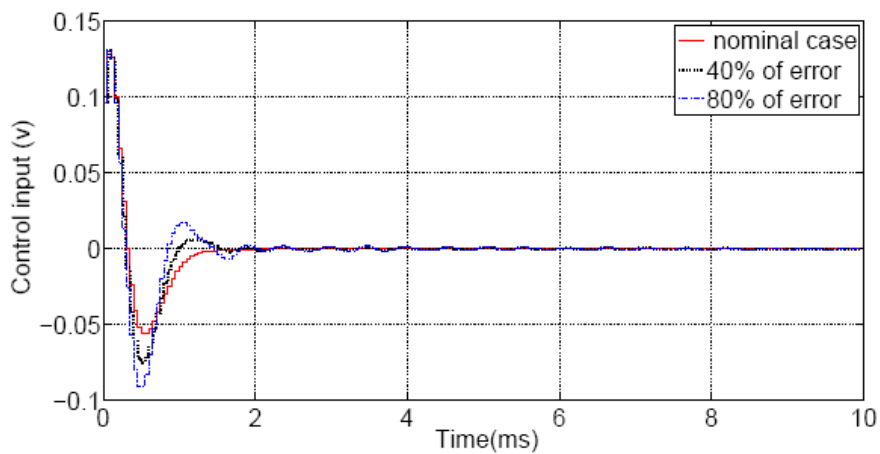

(b)

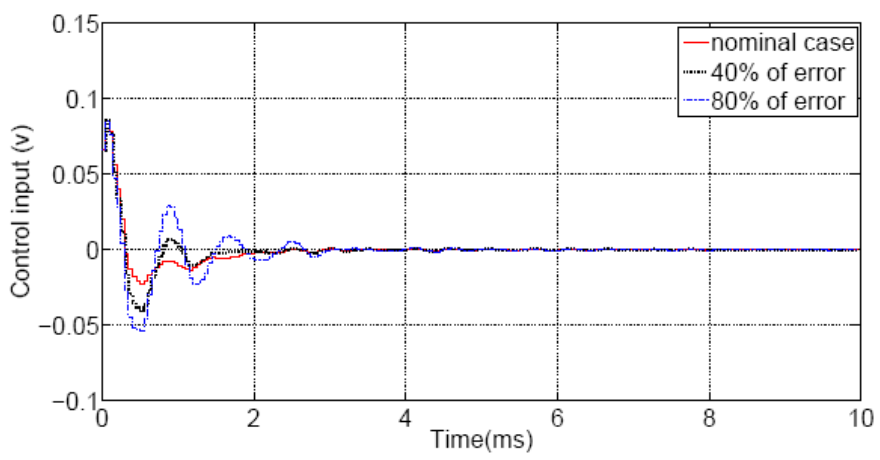

(c)

Table 3 Controllers synthesis parameters

\begin{tabular}{cccccccc}
\hline & $P I D$ & & \multicolumn{5}{c}{$M P C$} \\
\cline { 1 - 5 } \cline { 5 - 8 }$K_{p}$ & $K_{i}$ & $K_{d}$ & & $h_{p}$ & $h_{c}$ & $Q$ & $R$ \\
\hline 0.1 & 0.005 & 0.5 & & 4 & 3 & $0.01 \times I$ & $0.01 \times I$ \\
\hline
\end{tabular}


Table 4 Controllers performance comparison in low frequencies

\begin{tabular}{lcc}
\hline Nominal case & PID controller & NMPC controller \\
\hline Settling time & $2.07 \mathrm{~ms}$ & $0.33 \mathrm{~ms}$ \\
Maximum overshoot & $31 \%$ & $4 \%$ \\
\hline Punctual disturbance & & \\
\hline Settling time & $1.1 \mathrm{~ms}$ & $0.18 \mathrm{~ms}$ \\
Recovery time & $4.1 \mathrm{~ms}$ & $0.4 \mathrm{~ms}$ \\
\hline Parameters uncertainties (40\% of inertial mass error) & & \\
\hline Settling time & $1.71 \mathrm{~ms}$ & $0.23 \mathrm{~ms}$ \\
Maximum overshoot & $38 \%$ & $6 \%$ \\
\hline
\end{tabular}

Figure 12 Track following problem in nominal conditions with NMPC controller, (a) output displacement (b) control input (see online version for colours)

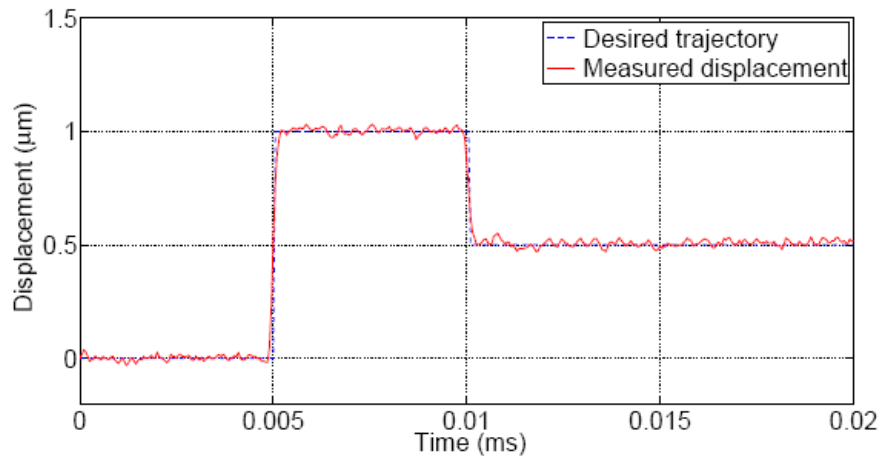

(a)

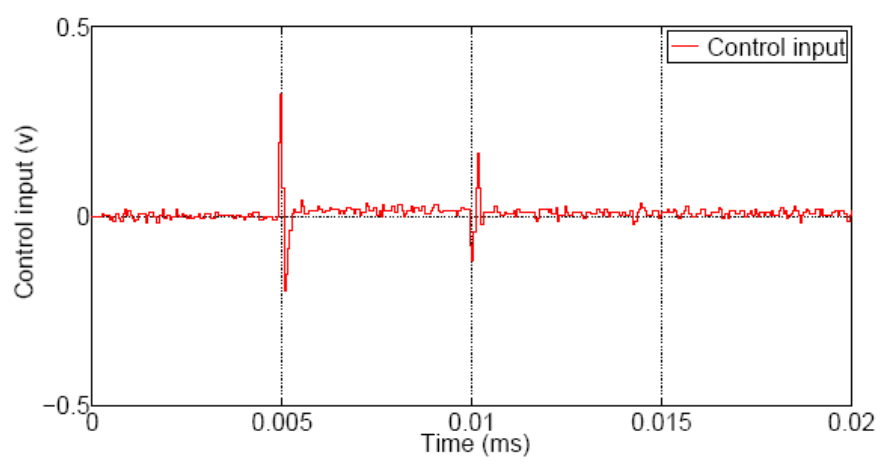

(b) 
Figure 13 Track following problem in nominal conditions with PID controller, (a) output displacement (b) control input (see online version for colours)

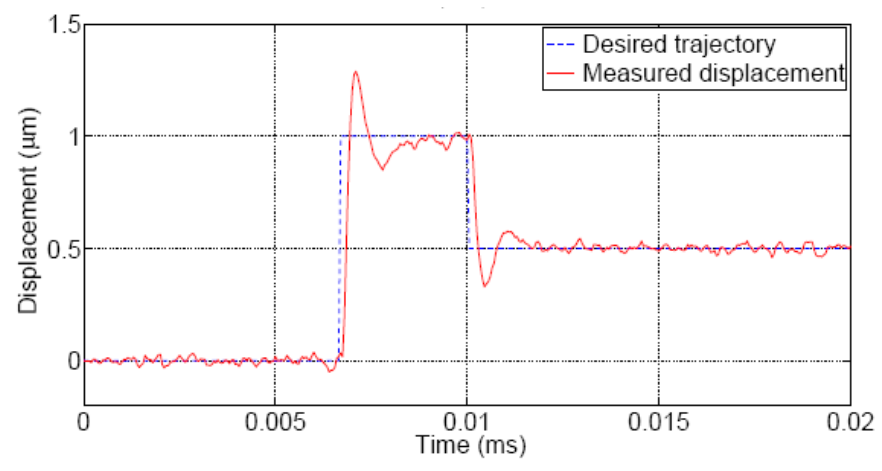

(a)

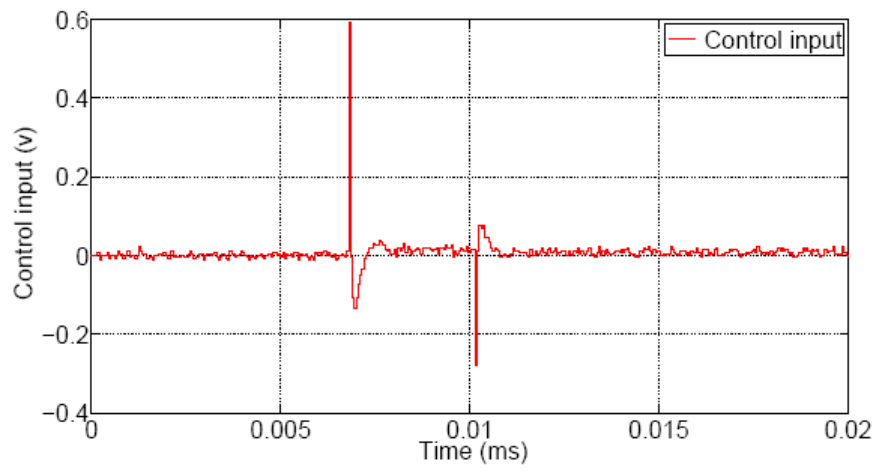

(b)

\subsubsection{Scenario 1: nominal case with a measurement noise consideration}

Figure 12 and Figure 13 show the response of the nonlinear closed-loop system with a measurement noise. The variance of the considered noise is $\sigma^{2}=0.9 \times 10^{-4}(\mu \mathrm{m})^{2}$. The predictive behaviour of the NMPC controller is clearly seen in Figure 12 where the VCM actuator begins to reach the reference position $h_{p}$ samples in advance. Moreover, NMPC design method yields a fast 5\% settling time with a significant smaller overshoot compared to the classical PID response. One can therefore conclude that NMPC controller is able to compensate the effect of friction and nonlinearities to achieve a better rapid and precise head positioning of HDD servo-system.

\subsubsection{Scenario 2: impulse disturbance rejection}

The control performances of the NMPC and PID with a constant reference are shown in Figure 14 and Figure 15. The robustness against external disturbance is well demonstrated with the NMPC controller. Indeed, it can be clearly seen that unexpected responses are rejected and the actuator returns to its desired trajectory rapidly and accurately. Furthermore, it is worth noting that the recovery time with the NMPC technique is much less than with the classical PID controller with smaller overshoots. 
Figure 14 Track following problem with punctual disturbance with NMPC controller, (a) output displacement (b) control input (see online version for colours)

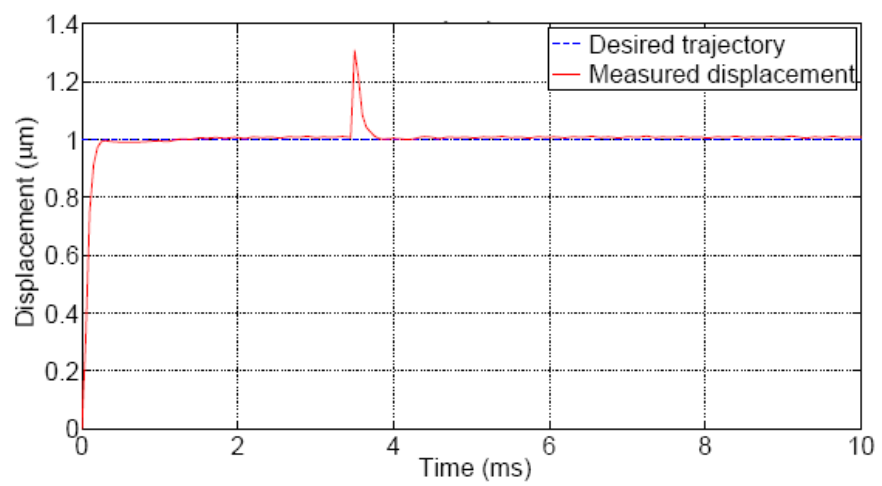

(a)

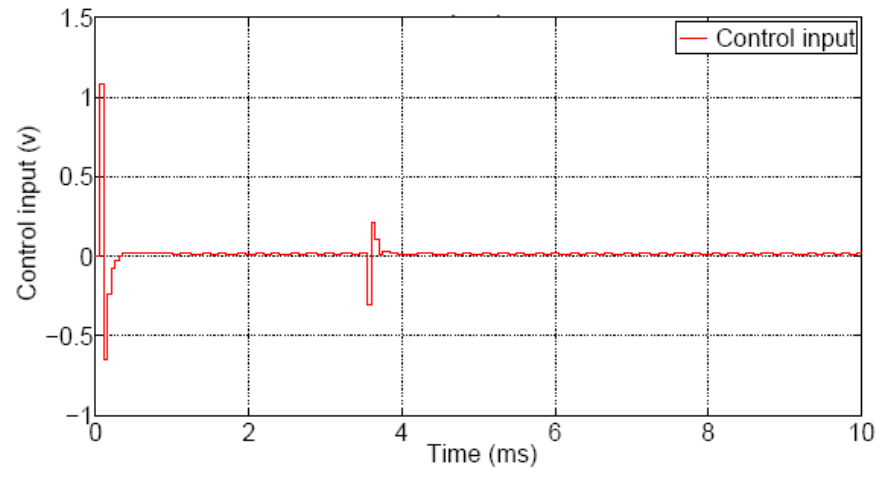

(b)

\subsubsection{Scenario 3: robustness against parameters uncertainty: variation on the mass inertia}

Simulation results are presented in Figure 16, Figure 17 and Figure 18. First, we have tested the response of the proposed solutions for uncertainties of $20 \%$ and $40 \%$ on the system inertia/mass constant (7). This uncertainty is due to the displacement of the $\mathrm{R} / \mathrm{W}$ head which makes the parameter not perfectly known. With the classical PID controller, the output movement and the control input are heavily affected and their response is degraded: significant oscillations and longer time required to converge to the reference trajectory. NMPC controller is sufficiently effective with up to $40 \%$ uncertainties and the convergence to the desired trajectory is well achieved. For larger uncertainties of $100 \%$ and $200 \%$ of the inertia/ mass as depicted in Figure 17, the response is roughly similar to that obtained with the PID controller with $20 \%$ and $40 \%$ errors. Therefore, NMPC controller is capable of delivering good performance in track-following test for nonlinear HDD model and in the presence of large uncertainties on parameters unlike the PID controller. 
Figure 15 Track following problem with punctual disturbance with PID controller, (a) output displacement (b) control input (see online version for colours)

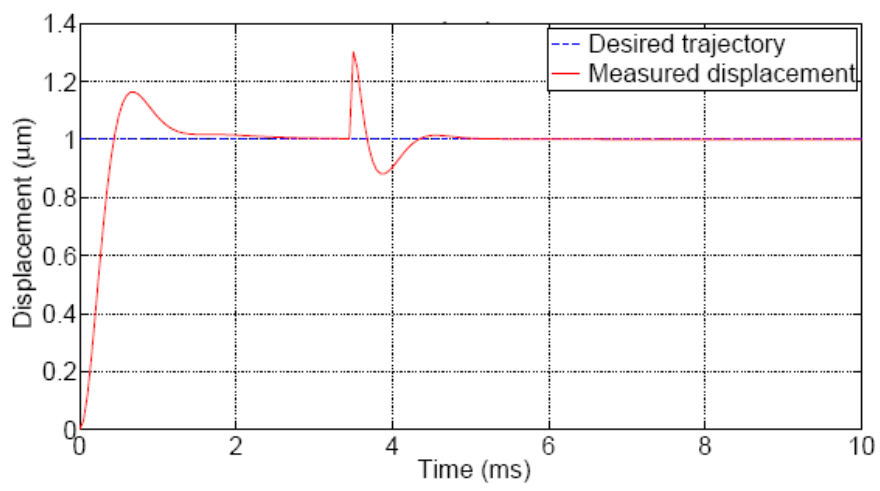

(a)

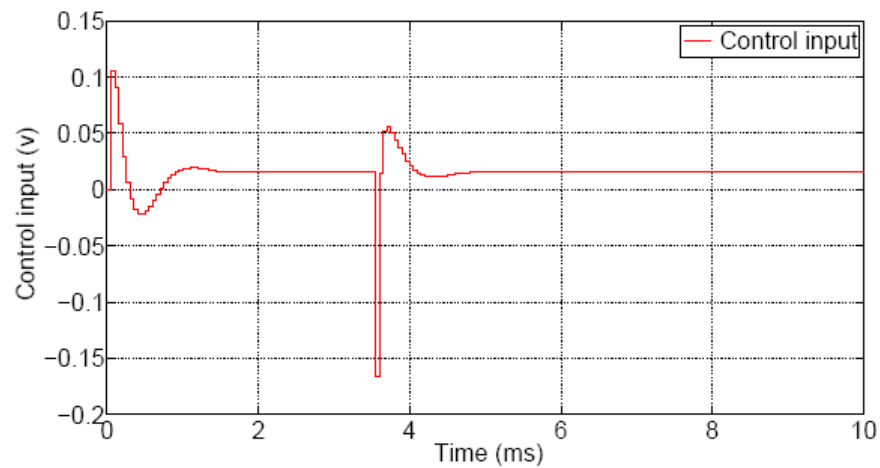

(b)

Figure 16 Robustness towards parameter uncertainty: (20\% and $40 \%$ of error): plots with NMPC, (a) output displacement (b) control input (see online version for colours)

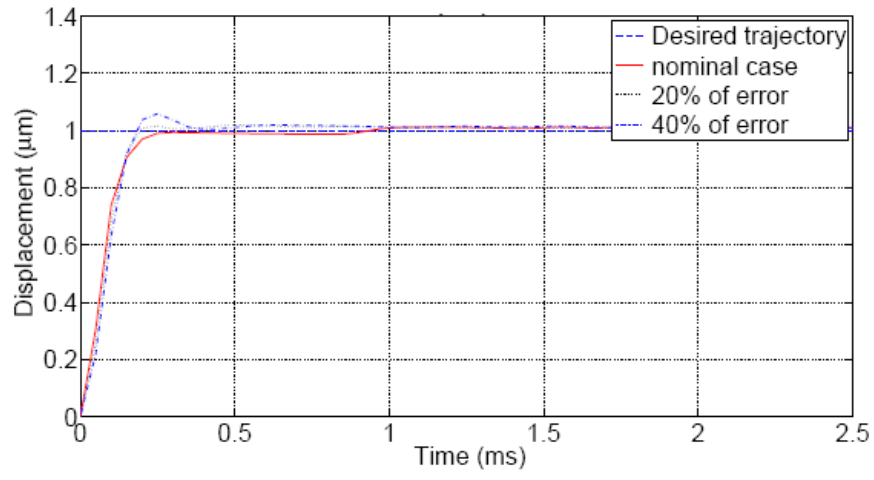

(a) 
Figure 16 Robustness towards parameter uncertainty: (20\% and 40\% of error): plots with NMPC, (a) output displacement (b) control input (continued) (see online version for colours)

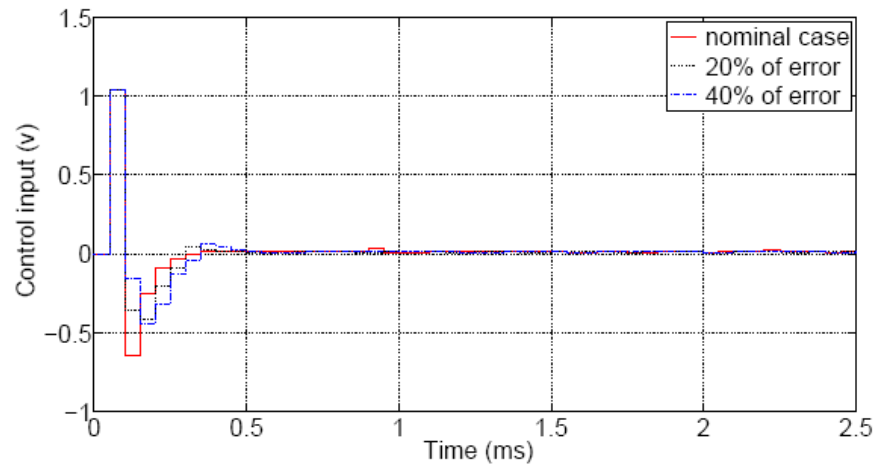

(b)

Figure 17 Robustness towards parameter uncertainty with PID controller ( $20 \%$ and $40 \%$ of error), (a) output displacement (b) control input (see online version for colours)

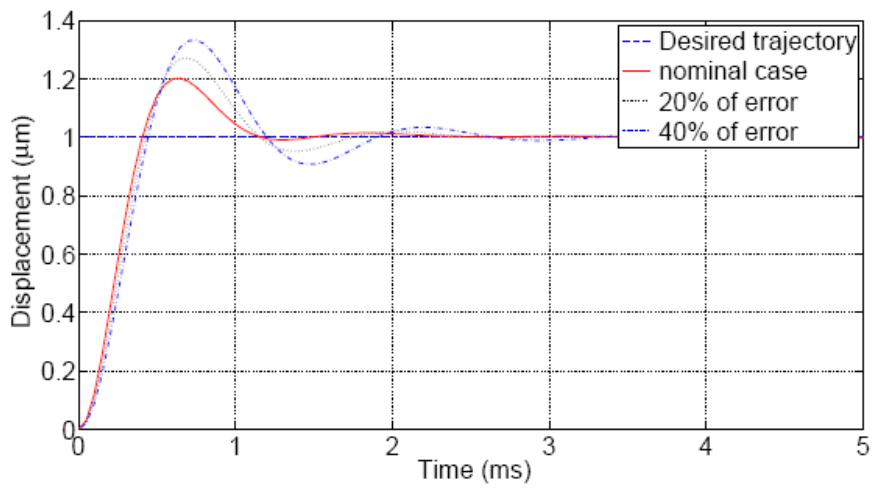

(a)

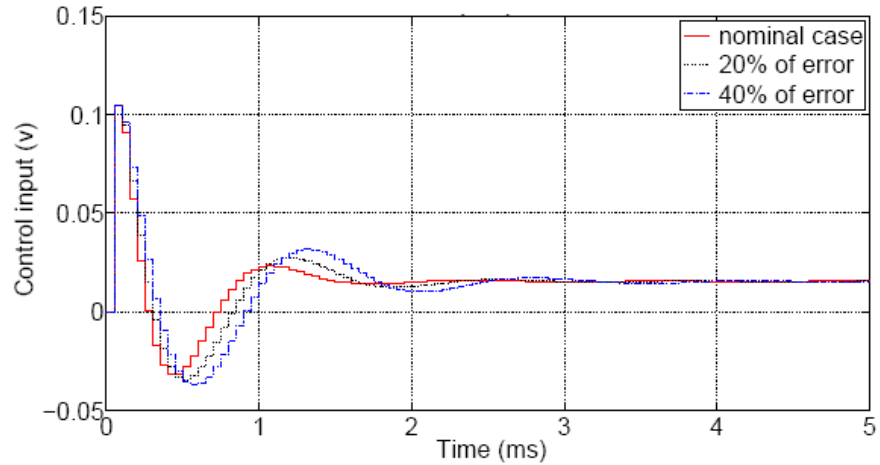

(b) 
Figure 18 Robustness towards parameter uncertainty with NMPC (100\% and 200\% of error), (a) output displacement (b) control input (see online version for colours)

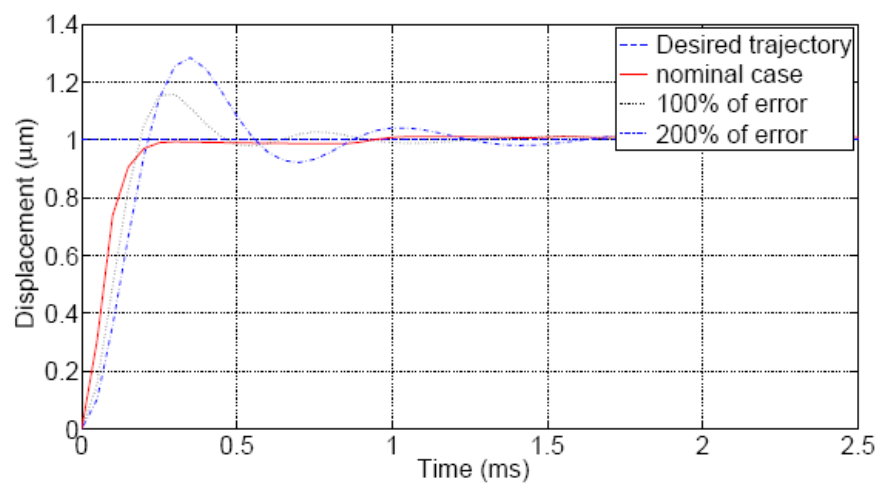

(a)

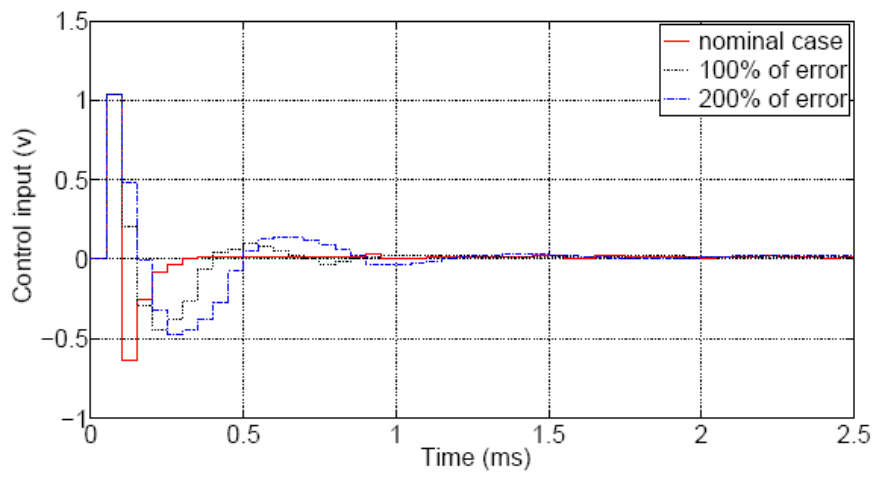

(b)

\section{Concluding remarks and future work}

Different control algorithms originated from model predictive control (MPC) strategy to solve the track-following problem of a VCM actuator have been proposed in this paper. These algorithms have never been previously applied to such servo-system. The proposed solutions have been demonstrated in nominal cases as well as in different operating conditions in order to evaluate their robustness against external disturbances and parameter uncertainties. The control strategies have been analysed in two different frequency domains of the HDD servo-system. At high frequencies, the HDD servo-system is modelled as a second-order transfer function displaying some resonance modes. Classical MPC and the approach with multiple coincidence points (MPC-CP), are proposed to deal with the displacement control of the $\mathrm{R} / \mathrm{W}$ head of the servomechanism. The MPC-CP controller has a much better performance in the reference tracking compared to those of the linear MPC and classical PID controller. In addition, superior disturbance rejection and mitigation of parameter changes were observed with an MPC-CP technique than the two other controllers. At low frequencies, because of the friction and nonlinearities of the VCM actuator, a NMPC has been proposed in this paper 
to compensate for-all these unexpected elements in the servo-system. Simulation results have shown accurate positioning of the R/W head and reduction of the settling time with very minimal overshoots, compared to those with a PID controller. Moreover, simulation results confirmed the robustness of proposed controller under different operating conditions, and control input constraints. It is shown that the actuator is precisely and quickly maintained closer to the desired position satisfying constraints, rejecting external disturbances and effectively dealing with parameter uncertainties. Further, research directions will involve the implementation of the different proposed controllers in a real HDD servo system.

\section{References}

Atsumi, T. et al. (2007) 'Track-following control using resonant filter in hard disk drives', IEEE/ASME Transactions on Mechatronics, Vol. 12, No. 4, pp.472-479.

Bhattacharya, R. et al. (2002) 'Nonlinear receding horizon control of an F-16 aircraft', Journal Guidance Control and Dynamics, Vol. 25, No. 5, pp.924-931.

Boettcher, U. et al. (2010) 'Modeling and control of a dual actuator servo system for hard disk drives', Journal of Advanced Mechanical Design, Systems, and Manufacturing, Vol. 4, No. 1, pp.107-118.

Camacho, E. and Bordons, C. (2004) Model predictive Control, Springer-Verlag, London.

Chen, B. et al. (2003) 'Composite nonlinear feedback control for linear systems with input saturation: theory and an application', IEEE Transaction on Automatic Control, Vol. 48, No. 3, pp.427-439.

Chen, B. et al. (2006) Hard Disc Drive Servo-Systems, Springer, Germany.

Clark, D. (1994) Advances in Model-Based Predictive Control, Oxford University Press, Oxford, USA.

Clarke, C. et al. (1987) 'Generalized predictive control: I-the basic algorithm and II-extensions and interpretations', Automatica, Vol. 23, No. 2, pp.137-160.

Clarke, D. (1988) 'Application of generalized predictive control to industrial processes', IEEE Control Systems Magazine, Vol. 8, No. 2, pp.49-55.

Cueli, J. and Bordons, C. (2008) 'Iterative nonlinear model predictive control. Stability, robustness and applications', Control Engineering Practice, Vol. 16, No. 9, pp.1023-1034.

Cutler, C. and Ramaker, B. (1980) 'Dynamic matrix control - a computer control algorithm', in Automatic Control Conference, San Francisco, USA.

Eaton, J. and Rawlings, J. (1992) 'Model predictive control of chemical processes', Chemical Engineering Science, Vol. 47, No. 4, pp.705-720.

Garca, C. et al. (1989) 'Model predictive control: theory and practice - a survey', Automatica, Vol. 25, No. 3, pp.335-348.

Goh, Z. and Li, T.B. et al. (2001) 'Design and implementation of a hard disk drive servo system using robust and perfect tracking approach', IEEE Transaction on Control Systems Technology, Vol. 9, No. 2, pp.221-233.

Graham, M. and De Callafon, R. (2006) 'Modeling and robust control for hard disk drives', in ASME/JSM Conference on Micromechatronics for information and Precision Equipment (MIPE), Santa Carla, CA, USA.

Hirata, M. et al. (2003) 'Track-following control of hard disk drives using multi-rate sampled-data $\mathrm{H}_{\infty}$ control', in Proc. 42nd Conference on Decision and Control, Maui, Hawaii, USA, Vol. 4, pp.3414-3419.

Horowitz, R. and Li, B. (1995) 'Adaptive control for disk file actuators', in Proc. 34th Conference on Decision and Control, New Orleans, LA, Vol. 1, pp.655-660. 
Isayed, B. and Hawwa, M. (2007) 'A nonlinear PID control scheme for hard disk drive servo-systems', in MED 07, Mediterranean Conference on Control and Automation, pp.1-6.

Ishikawa, J. and Tomizuka, M. (1998) 'A novel add-on compensator for cancellation of pivot nonlinearities in hard disk drives', IEEE Transactions on Magnetics, Vol. 34, No. 4, pp.1895-1897.

Kobayashi, M. et al. (2004) 'Adaptive control of dual-stage-actuator for hard disk drives', in Proc. American Control Conference, Boston, MA, USA, Vol. 1, pp.523-528.

Lee, C. and Suh, S. (2011) 'Model prediction based dual-stage actuator control in discrete-time domain', IEEE Transaction on Magnetics, Vol. 47, No. 7, pp.1830-1836.

Li, Q. et al. (1997) 'Analysis of the dynamics of 3.5" hard disk drive actuators', Tech. rep., Data Storage Institute, Singapore.

Maciejowski, J. (2002) Predictive Control with Constraints, Prentice Hall, England.

Mayne, D. and Michalska, H. (1990a) 'Receding horizon control of nonlinear systems', IEEE Transaction on Automatic Control, Vol. 35, pp.814-824.

Mayne, D. et al. (2000) 'Constrained model predictive control: stability and optimality', Automatica, Vol. 36, pp.789-814.

Nicolao, G.D. et al. (1998) 'Stabilizing receding-horizon control of nonlinear time-varying systems', IEEE Transaction on Automatic Control, Vol. 43, No. 7, pp.1030-1036.

Nie, J. et al. (2011) 'Optimal $\mathrm{H}_{\infty}$ control for hard disk drives with an irregular sampling rate', in American Control Conference, CA, USA.

Piché, S. et al. (2000) 'Nonlinear model predictive control using neural networks', IEEE Control Systems Magazine, Vol. 20, No. 3, pp.53-62.

Qin, S. and Badgwell, T. (1996) 'An overview of industrial model predictive control technology', Chemical Process Control, Vol. 11, No. 7, pp.733-764.

Qin, S. and Badgwell, T. (2003) 'A survey of industrial model predictive control technology', Control Engineering Practice, Vol. 11, pp.733-764.

Rawlings, J. et al. (1994) 'Nonlinear model predictive control: a tutorial and survey', ADCHEM'94 Proceedings.

Susanu, M. et al. (2007) 'Virtual machine-tool environment: design and validation', in 6th International Conference on High Speed Machining, San Sebastian, Spain.

Taktak, M. et al. (2012) 'Track following problem of a VCM actuator servo system for hard disc drives using predictive control', in 9th International Multi-Conference on Systems, Signals and Devices, Chemnitz, Germany, pp.1-7.

Taktak, M. et al. (2013) 'Model predictive tracking control for a head-positioning in a hard-disk-drive', in Proc. 21st Mediterranean Conference on Control and Automation, Platanias, Chania, Crete, Greece.

Venkataramanan, V. et al. (2002) 'A new approach to the design of mode switching control in hard disk drive servo systems', Control Engineering Practice, Vol. 10, No. 9, pp.925-939.

Yamaguchi, T. and Hirai, H. (1998) 'Control of transient response on a servo-system using mode-switching control, and its application to magnetic disk drives', Control Engineering Practice, Vol. 6, No. 9, pp.1117-1123.

Yamaguchi, T. et al. (1997) 'A mode-switching controller with initial value compensation for hard disk drive servo control', Control Engineering Practice, Vol. 5, No. 11, pp.1525-1532. 